\title{
Efficient trawl avoidance by mesopelagic fishes causes large underestimation of their biomass
}

\author{
Stein Kaartvedt ${ }^{1,2, *}$, Arved Staby ${ }^{3,4}$, Dag L. Aksnes ${ }^{3}$ \\ ${ }^{1}$ King Abdullah University of Science and Technology, Red Sea Research Center, Thuwal 23955-6900, Saudi Arabia \\ ${ }^{2}$ Department of Biology, University of Oslo, 0316 Oslo, Norway \\ ${ }^{3}$ Department of Biology, University of Bergen, 5020 Bergen, Norway \\ ${ }^{4}$ Present address: Institute of Marine Research, 5817 Bergen, Norway
}

\begin{abstract}
Mesopelagic fishes occur in all the world's oceans, but their abundance and consequently their ecological significance remains uncertain. The current global estimate based on net sampling prior to 1980 suggests a global abundance of one gigatonne $\left(10^{9} \mathrm{t}\right)$ wet weight. Here we report novel evidence of efficient avoidance of such sampling by the most common myctophid fish in the Northern Atlantic, i.e. Benthosema glaciale. We reason that similar avoidance of nets may explain consistently higher acoustic abundance estimates of mesopelagic fish from different parts of the world's oceans. It appears that mesopelagic fish abundance may be underestimated by one order of magnitude, suggesting that the role of mesopelagic fish in the oceans might need to be revised.
\end{abstract}

KEY WORDS: Mesopelagic fish - Avoidance behavior . Trawling $\cdot$ Acoustics

Resale or republication not permitted without written consent of the publisher

\section{INTRODUCTION}

Mesopelagic (200 to $1000 \mathrm{~m}$ depth) fishes are important planktivores and prominent prey for higher trophic levels in all the world's oceans (Gjøsæter \& Kawaguchi 1980, Lam \& Pauly 2005) and, because of pronounced diel vertical migrations (DVM), contribute to the biological pump whereby organic material is transported from upper layers down to the waters at depth (Hidaka et al. 2001, Hernández-León et al. 2010). The current global bio-

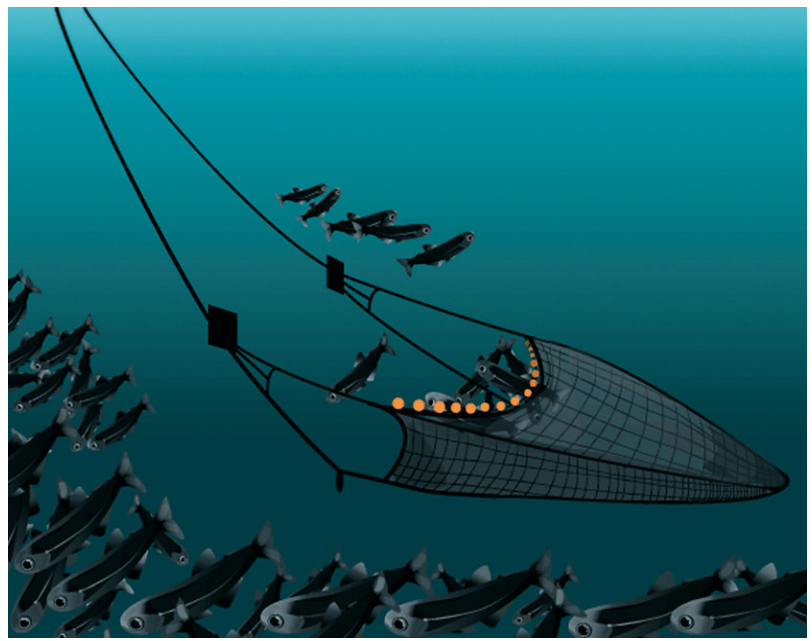

Mesopelagic fishes show efficient avoidance behavior in response to sampling gears.

Image: Hege Vestheim

mass estimate of mesopelagic fishes, primarily based on catches by micronekton sampling gears prior to 1980 , amounts to approximately 1 gigatonne $\left(10^{9} \mathrm{t}\right.$ wet weight) (Gjøsæter \& Kawaguchi 1980, Lam \& Pauly 2005). This is likely an underestimate (Gjøsæter \& Kawaguchi 1980) because mesopelagic fishes are not captured quantitatively by sampling gear. Subsequent gear intercomparisons have revealed marked differences in catch efficiency of mesopelagic fish between different trawl types, due to various influences from extrusion through meshes and net avoid- 
ance behavior (Pakhomov \& Yamamura 2010, Heino et al. 2011). However, regardless of trawl type, acoustic abundance estimates always appear to be consistently higher than the net-based estimates (Koslow et al. 1997, Kloser et al. 2009, Pakhomov \& Yamamura 2010).

Myctophids (lanternfish) are the most widespread mesopelagic fish family (Saito \& Murata 1998), being represented by $\sim 250$ species worldwide (Catul et al. 2011). Facilitated by the unique opportunities deep fjords provide for investigating the mesopelagic realm (Kaartvedt et al. 2009), we used echo sounders to obtain novel evidence of pronounced avoidance of a trawl by the most common myctophid fish in the Northern Atlantic, i.e. Benthosema glaciale. Our results suggest that the sampling gear invokes avoidance reactions similar to those incited by approaching predators and that such efficient avoidance behavior will cause large net-based underestimation of mesopelagic fish biomass.

\section{MATERIALS AND METHODS}

Sampling and acoustic studies of avoidance of a trawl were carried out in Masfjorden (60 52' N, $\left.5^{\circ} 25^{\prime} \mathrm{E}\right)$, Norway, on 2-3 November 2007, using the RV 'Håkon Mosby' (University of Bergen and Institute of Marine Research). Two mesopelagic fish species prevail in Masfjorden: Maurolicus muelleri dominates in the upper $200 \mathrm{~m}$, while Benthosema glaciale is mostly distributed below $200 \mathrm{~m}$ and is the prevailing species below $\sim 250 \mathrm{~m}$ (Kaartvedt et al. 2009, Staby et al. 2011, Dypvik et 2012). Both species to a varying degree carry out DVM, depending on season (Kaartvedt et al. 2009, Staby et al. 2011, Dypvik et 2012). At the time of the present study (late fall), the population of adult $M$. muelleri had largely ceased migrating vertically (Staby et al. 2011). In the nocturnal echograms presented here, they likely dominated the acoustic backscatter above $200 \mathrm{~m}$ (see Fig. 1), but they are not further dealt with in this paper, where we focus on fish in deeper waters. B. glaciale mostly stayed below $200 \mathrm{~m}$ at night (Kaartvedt et al. 2009).

We used a Harstad trawl, designed to capture small fish, which had un-stretched mesh sizes ranging from $200 \mathrm{~mm}$ in the front to $10 \mathrm{~mm}$ in the rear part. Trawl height and width is $\sim 20 \mathrm{~m}$, which provides an opening of $\sim 400 \mathrm{~m}^{2}$, the area used for calculations of volume filtered. This evidently is an overestimate of the unknown 'effective' mouth opening, which will result in an underestimate of true fish abundance.
Pelagic trawls with decreasing meshes towards the cod-end are intended to herd fish backwards until they eventually encounter meshes that are small enough for retention (e.g. Lee et al. 1996, Heino et al. 2011). Nevertheless, there will be an unknown fraction of the catch escaping through coarse meshes in the front.

The trawl was towed at 2 to 3 knots. It was equipped with a remotely controlled Multisampler cod-end (Engås et al. 1997) that was kept open during launching and retrieval of the trawl. Trawl depth was monitored during sampling by a Scanmar depth sensor located at the head rope of the trawl. Acoustic transects using the RV 'Håkon Mosby's Simrad EK60 $38 \mathrm{kHz}$ echo sounder $\left(7,1^{\circ}\right.$ beam width) were carried out prior to, during and subsequent to a tow conducted at $\sim 320$ to $330 \mathrm{~m}$ depth at night; in the latter case, the vessel traversed the path of the preceding tow, assessing the distribution and abundance of mesopelagic fish along the path of the trawl.

We made acoustic abundance estimates of Benthosema glaciale for the same depth and horizontal segments as the trawling, using the software Echoview. After backscatter from individual, larger fish had been removed, the remaining volume backscattering $\left(\mathrm{S}_{\mathrm{v}}\right)$ in a rectangle corresponding to the depth of the subsequent sampling was allocated to B. glaciale. This is largely justified based on trawl catches in this and other studies, as well as from acoustic studies at different frequencies (Kaartvedt et al. 2008, Kaartvedt et al. 2009, Dypvik et 2012, although some backscatter from pelagic shrimps may have been included in the estimate. For converting total $S_{v}$ values to number of fish, we used the standard relation: $\mathrm{N}=10^{\left[\left(\mathrm{S}_{\mathrm{v}}-\right.\right.}$ TS)/10] (MacLennan \& Simmonds 1992), where $N$ is number of fish and TS (target strength) is the acoustic backscatter from one individual.

In situ values for TS of individual fish were obtained by an upward-facing, calibrated echo sounder (Simrad EK60, $38 \mathrm{kHz}, 7.1^{\circ}$ beam width) deployed on the bottom at $390 \mathrm{~m}$ depth in the same fjord location and cabled to shore for long-term measurements (July 2007 to October 2008). This provided a TS of $-58.4 \mathrm{~dB}$ for Benthosema glaciale during the time of this study (Kaartvedt et al. 2009). Sizes of B. glaciale in catches below $300 \mathrm{~m}$ were $59 \pm 5 \mathrm{~mm}$ (SD) and $60 \pm 5 \mathrm{~mm}$ for day and night, respectively (Kaartvedt et al. 2009).

For comparison with avoidance of the trawl, data from the long-term acoustic measurements were also used to assess avoidance behavior of Benthosema glaciale upon encounters with groups (here referred to as 'schools') of potentially predatory fish. 


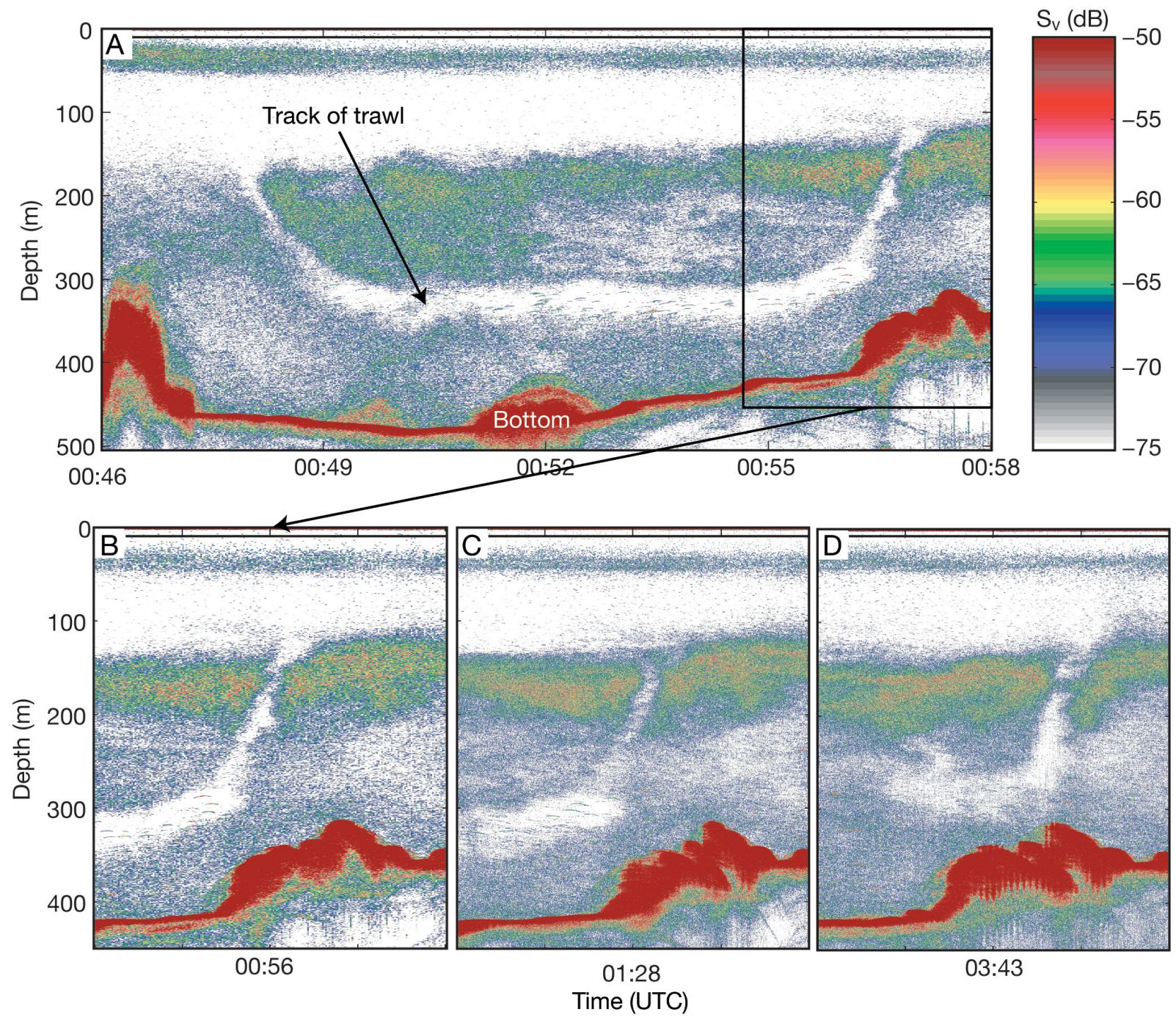

Fig. 1. Avoidance of trawl. (A) Echogram recorded when the path of a preceding trawl tow was traversed; signature with low backscatter depicts the track of the trawl. (B-D) Persistence of the void created by the trawl (deployed at $\sim 23: 30 \mathrm{~h}$ ). The trawl had free throughflow and was not sampling on its way down (the part of the tow portrayed in B-D), so the void in the acoustic records cannot be explained by removal of fish by the gear. Color scale refers to volume backscattering strength $\left(\mathrm{S}_{\mathrm{v}}\right)$, with brownish-red as the strongest echoes

\section{RESULTS}

A conspicuous trace (void) in the acoustic scattering layers of mesopelagic fish appeared when the path of a preceding nocturnal trawl tow of the mesopelagic was traversed while acoustic measurements were made (Fig. 1A). This void persisted for several hours in the calm fjord environment, drifting slowly at 2 to $3 \mathrm{~cm} \mathrm{~s}^{-1}$ (Fig. 1B-D). The void also mirrors the periods of launching and retrieval of the trawl when a remotely controlled cod-end is kept open so that there is free flow through the trawl, i.e. no capture of fish. Catches in 4 trawl samples below $300 \mathrm{~m}$, including the tow responsible for the void shown in Fig. 1, were $58 \pm 12$ (SE) Benthosema glaciale, correspond- ing to $\sim 0.05 \pm 0.01$ ind. per $100 \mathrm{~m}^{3}$. The acoustic abundance estimates of $B$. glaciale for the same depth and horizontal segments as the trawling were $3.6 \pm 0.5$ (SE) ind. per $100 \mathrm{~m}^{3}$.

We made observations of natural predator avoidance behavior of mesopelagic fish (Benthosema glaciale) from the bottom-mounted echo sounder (Fig. 2). Undisturbed individuals normally remain motionless, resulting in echo traces appearing as horizontal 'lines' since many successive echoes are received from the same individual. Nevertheless, encounters with schools of larger fish incite pronounced escape reactions (Fig. 2). Individuals diving below the-presumably predatory - school are evident in the acoustic records (Fig. 2B). Also, a $50 \%$ increase in acoustic 


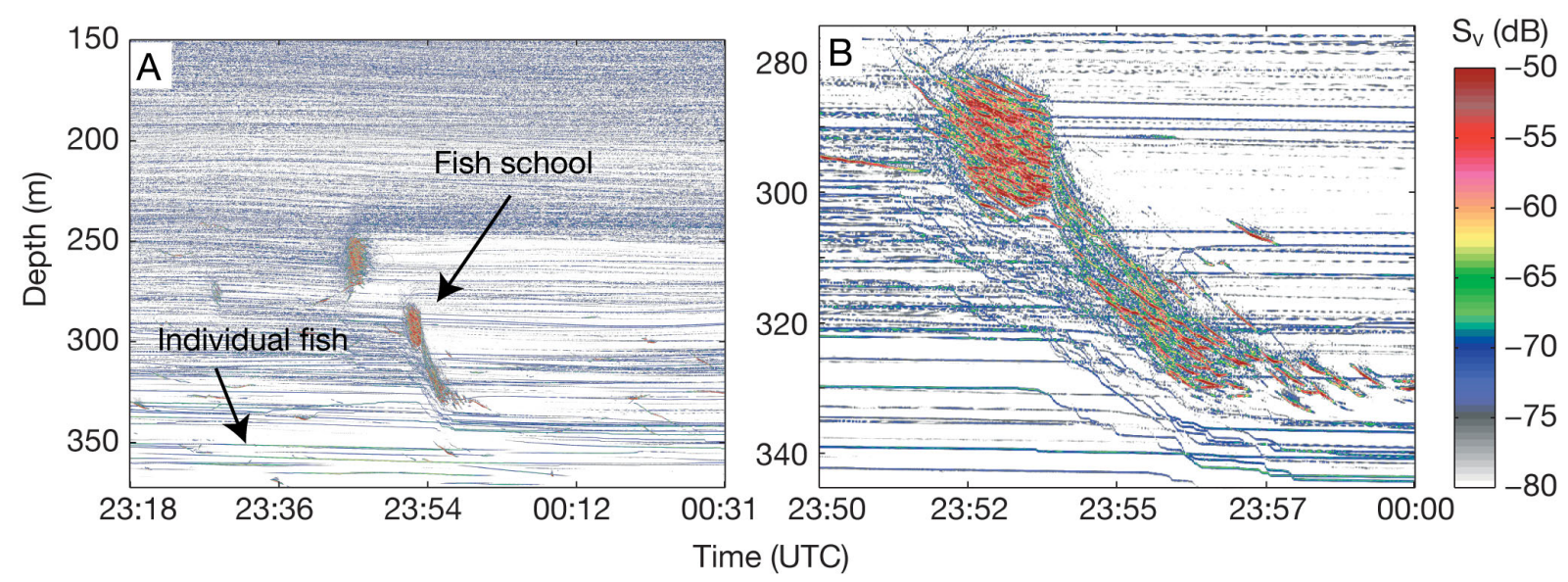

Fig. 2. Benthosema glaciale. Avoidance of predators. (A) Mesopelagic fish (individuals seen as blue 'lines') escape from a school of larger fish, creating a comparative void as in Fig. 1. (B) Close up, excerpt from (A). Records were made by an echo sounder deployed at $390 \mathrm{~m}$ depth; color scale refers to volume backscattering strength $\left(\mathrm{S}_{\mathrm{v}}\right)$, with brownish-red as the strongest echoes

backscatter is recorded throughout the nearest $20 \mathrm{~m}$ above the school. This suggests additional upwards escapement, but individuals cannot be observed at this range from the echo sounder. The largest vertical distance between the school and a responding fish suggests that the approaching school is detected within a range of $\sim 30 \mathrm{~m}$.

After the encounter with the predators, the fishes resumed a lethargic behavior, leaving a persistent void in the acoustic records, much as that recorded in the wake of the trawl. This type of flight behavior upon encounter with predators was repeatedly recorded during the long-term acoustic measurements.

\section{DISCUSSION}

Our acoustic results clearly suggest avoidance behavior of mesopelagic fish from a pelagic trawl. Marked voids in the acoustic records of Benthosema glaciale (and of the shallower located Maurolicus muelleri, which is not further addressed here) encompassed periods when the trawl was kept open and thus without capture of fish, suggesting that the void is created by fish swimming away from the trawl rather than removal of fish. The void created by the trawl was similar to the void formed as a result of $B$. glaciale escaping potential predatory fishes. In both cases, the voids persisted, since B. glaciale resumed their lethargic behavior immediately after their flight behavior. The well-documented pattern of quiescence in mesopelagic fish (Barham 1966) evidently does not prevent prompt flight reactions.

The void created by the trawling had a vertical extent of about $30 \mathrm{~m}$, which is $10 \mathrm{~m}$ greater than the trawl opening. The diameter of the acoustic beam at $315 \mathrm{~m}$ depth is $40 \mathrm{~m}$, suggesting a minimum for the horizontal extension of the void, and underlining the extent of the avoidance behavior. The behavioral observations of encounters between Benthosema glaciale and fish schools suggested that predators could be detected at a range of tens of meters. Fish can use several sensory stimuli to detect a moving trawl (Handegard \& Tjøstheim 2005, Jamieson et al. 2006). This includes visual detection (Jamieson et al. 2006, Heino et al. 2011), and catches of myctophids have been considered to be more quantitative at night (Collins et al. 2012). However, trawls will stimulate bioluminescent flashes (Jamieson et al. 2006) and thereby also make a marked visual signal at night. Myctophids have eyes that are very sensitive to light, and bioluminescent flashes may be detected at a range of tens of meters (Warrant \& Locket 2004). While the actual mechanisms eliciting avoidance behavior is beyond the scope of this paper, visually stimulated nocturnal avoidance may very well be expected.

Acoustic abundance estimates were close to 2 orders of magnitude higher than estimates from the trawl and were roughly similar to previous acoustic estimates of Benthosema glaciale from Masfjorden (Bagøien et al. 2001). However, our trawl catches were lower than previous net sampling in the fjord (Kaartvedt et al. 1988, Giske et al. 1990), suggesting a lower sampling efficiency for the trawl used in our study than for the smaller gears normally used in mesopelagic studies (Gjøsæter \& Kawaguchi 1980). Although not concurrent in time, results from the previous studies in Masfjorden suggest differences between net-based and acoustic abundance esti- 
mates closer to one order of magnitude. Correspondingly, studies from other parts of the worlds' oceans also give acoustic abundance estimates of mesopelagic fish about one order of magnitude higher than net-based estimates (Koslow et al. 1997, Kloser et al. 2009, Pakhomov \& Yamamura 2010).

Acoustic estimates are also affected by uncertainties and depend on fish size distribution relative to acoustic wave length, correct ascribing of acoustic backscatter to fish in scattering layers composed of different taxonomic groups, and use of appropriate TS values (Barham 1966, MacLennon \& Simmonds 1992, Godø et al. 2009). However, such uncertainties do not relate to our direct observations of avoidance in the much-studied ecosystem of Masfjorden. Therefore, we conclude that efficient avoidance of sampling gear indeed causes large net-based underestimation of the most common myctophid in the northern Atlantic. To the extent that this conclusion can be generalized, our evidence suggests that avoidance may also account for pronounced discrepancies between net-based and acoustic abundance estimates of mesopelagic fishes that have been revealed in other studies.

The global estimate of mesopelagic fish that is commonly referred to in the scientific literature amounts to $948 \times 10^{6}$ t wet weight (Gjøsæter \& Kawaguchi 1980) and was slightly revised to $999 \times 10^{6} \mathrm{t}$ (Lam \& Pauly 2005) to correct for minor inconsistencies in the original estimation. More important is probably the likelihood of underestimation that was pointed out in Gjøsæter \& Kawaguchi (1980, p 121): 'most of the gears used to obtain the available information obviously underestimate the biomass present'. Due to lack of knowledge of the actual avoidance and underestimation of these fishes, this $30 \mathrm{yr}$ old estimate is still in use (Davison \& Asch 2011). If the underestimation suggested in this paper applies to the current global estimate (Gjøsæter \& Kawaguchi 1980), an acoustically determined mesopelagic fish biomass of $10^{10} \mathrm{t}$ is indicated for the world oceans.

A recent evaluation on the effect of fishing low trophic level species on marine ecosystems concludes that impacts of harvesting mesopelagic fishes would be consistently high across ecosystems (Smith et al. 2011). A potential upgrading of the current global estimate of mesopelagic fish to $10^{10} \mathrm{t}$ - which is 100 times larger than the world's yearly fishery catch - would force us to rethink their role as predators on zooplankton, as prey for top predators, as well as daily vertical transporters of organic matter from the surface to the deeper ocean.
Acknowledgements. We thank Anders Røstad and Thor A. Klevjer for help during the long-term acoustic study. Anders Røstad made the figures.

\section{LITERATURE CITED}

Bagøien E, Kaartvedt S, Aksnes DL, Eiane K (2001) Vertical distribution and mortality of overwintering Calanus. Limnol Oceanogr 46:1494-1510

Barham EG (1966) Deep scattering layer migration and composition: observations from a diving saucer. Science 151:1399-1403

Catul V, Gauns M, Karuppasamy PK (2011) A review on mesopelagic fishes belonging to family Myctophidae. Rev Fish Biol Fish 21:339-354

> Collins MA, Stowasser G, Fielding S, Shreeve R and others (2012) Latitudinal and bathymetric patterns in the distribution and abundance of mesopelagic fish in the Scotia Sea. Deep-Sea Res II 59-60:189-198

Davison P, Asch RG (2011) Plastic ingestion by mesopelagic fishes in the North Pacific Subtropical Gyre. Mar Ecol Prog Ser 432:173-180

Dypvik E, Røstad A, Kaartvedt S (2012) Seasonal variation in vertical migration of glacier lanternfish Benthosema glaciale. Mar Biol (in press)

Engås A, Skeide R, West CW (1997) The 'Multisampler': a system for remotely opening and closing multiple codends on a sampling trawl. Fish Res 29:295-298

Giske J, and others (1990) Vertical distribution and trophic interactions of zooplankton and fish in Masfjorden, Norway. Sarsia 75:65-82

Gjøsæter J, Kawaguchi KA (1980) A review of the world resources of mesopelagic fish. FAO Fish Tech Pap 193: $1-151$

Godø OR, Patel R, Pedersen G (2009) Diel migration and swimbladder resonance of small fish: some implications for analyses of multifrequency echo data. ICES J Mar Sci $66: 1143-1148$

> Handegard NO, Tjøstheim D (2005) When fish meet a trawling vessel: examining the behavior of gadoids using a free floating buoy and acoustic split-beam target tracking. Can J Fish Aquat Sci 62:2409-2422

Heino M, Porteiro FM, Sutton TT, Falkenhaug T, Godø OR, Piatkowski U (2011) Catchability of pelagic trawls for sampling deep-living nekton in the mid-North Atlantic. ICES J Mar Sci 68:377-389

- Hernández-León S, Franchy G, Moyano M, Menéndez I, Schmoker C, Putzeys S (2010) Carbon sequestration and zooplankton lunar cycles: Could we be missing a major component of the biological pump? Limnol Oceanogr 55:2503-2512

Hidaka K, Kawaguchi K, Murakami M, Takahashi M (2001) Downward transport of organic carbon by diel migratory micronekton in the western equatorial Pacific: its quantitative and qualitative importance. Deep-Sea Res I 48: 1923-1939

Jamieson AJ, Godø OR, Bagley PM, Partridge JC, Priede IG (2006) Illumination of trawl gear by mechanically stimulated bioluminescence. Fish Res 81:276-282

> Kaartvedt S, Aksnes DL, Aadnesen A (1988) Winter distribution of macroplankton and micronekton in Masfjorden, Western Norway. Mar Ecol Prog Ser 45:45-55

Kaartvedt S, Torgersen T, Klevjer TA, Røstad A, Devine JA (2008) Behavior of individual mesopelagic fish in 
acoustic scattering layers of Norwegian fjords. Mar Ecol Prog Ser 360:201-209

Kaartvedt S, Røstad A, Klevjer TA, Staby A (2009) Use of bottom-mounted echo sounders in exploring behavior of mesopelagic fishes. Mar Ecol Prog Ser 395:109-118

Kloser RJ, Ryan TE, Young JW, Lewis ME (2009) Acoustic observations of micronekton fish on the scale of an ocean: potential and challences. ICES J Mar Sci 66: 998-1006

Koslow JA, Kloser RJ, Williams A (1997) Pelagic biomass and community structure over the mid-continental slope off southeastern Australia based upon acoustic and midwater trawl sampling. Mar Ecol Prog Ser 146: 21-35

Lam WVY, Pauly D (2005) Mapping the global biomass of mesopelagic fishes. Sea Around Us Project Newsl 30:4

$>$ Lee KT, Lee MA, Wang JP (1996) Behavioural responses of larval anchovy schools herded within large-mesh wings of trawl net. Fish Res 28:57-69

Editorial responsibility: Jake Rice, Ottawa, Ontario, Canada
MacLennan DN, Simmonds EJ (1992) Fisheries acoustics. Chapman \& Hall, London

Pakhomov E, Yamamura O (2010) Report of the Advisory Panel on Micronekton Sampling Inter-calibration Experiment. PICES Scientific Report No. 38. North Pacific Marine Science Organization (PICES), Sidney, BC

Saito H, Murata M (1998) Origin of the monoene fats in the lipid of midwater fishes: relationship between the lipids of myctophids and those of their prey. Mar Ecol Prog Ser 168:21-33

Smith ADM, Brown CJ, Bulman CM, Fulton A and others (2011) Impacts of fishing low-trophic species on marine ecosystem. Science 333:1147-1150

Staby A, Røstad A, Kaartvedt S (2011) Long-term acoustical observations of the mesopelagic fish Maurolicus muelleri reveal novel and varied migration patterns. Mar Ecol Prog Ser 441:241-255

Warrant EJ, Locket NA (2004) Vision in the deep sea. Biol Rev Camb Philos Soc 79:671-712

Submitted: February 6, 2012; Accepted: April 26, 2012 Proofs received from author(s): May 16, 2012 